\title{
Inhibitory effects of sulfobacin B on DNA polymerase and inflammation
}

\author{
JUN MAEDA ${ }^{1}$, MASAYUKI NISHIDA ${ }^{1}$, HIROSATO TAKIKAWA ${ }^{3}$, HIROMI YOSHIDA ${ }^{4,5}$, \\ TAKESHI AZUMA ${ }^{1}$, MASARU YOSHIDA ${ }^{1,2}$ and YOSHIYUKI MIZUSHINA ${ }^{4,5}$ \\ ${ }^{1}$ Division of Gastroenterology, Department of Internal Medicine, ${ }^{2}$ The Integrated Center for Mass Spectrometry, \\ Graduate School of Medicine, Kobe University, 7-5-1 Kusunoki-Cho, Chuo-ku, Kobe, Hyogo 650-0017; \\ ${ }^{3}$ Department of Agrobioscience, Graduate School of Agricultural Science, Kobe University, Rokkodai, \\ Nada-ku, Kobe 657-8501; ${ }^{4}$ Laboratory of Food and Nutritional Sciences, Department of Nutritional \\ Science, Kobe-Gakuin University, Nishi-ku, Kobe, Hyogo 651-2180; ${ }^{5}$ Cooperative Research \\ Center of Life Sciences, Kobe-Gakuin University, Chuo-ku, Kobe, Hyogo 650-8586, Japan
}

Received June 14, 2010; Accepted August 12, 2010

\section{DOI: 10.3892/ijmm_00000522}

\begin{abstract}
The sulfonolipid, sulfobacin B, is isolated from Chryseobacterium sp. and functions both as a von Willebrand factor receptor antagonist and a DNA polymerase (pol) $\alpha$ inhibitor. Previously, we chemically synthesized sulfobacin B by starting from L-cysteine. In this study, we investigated the inhibitory effects of chemically synthesized sulfobacin B on the activity of pols and other DNA metabolic enzymes. Sulfobacin B selectively inhibited the activity of all animal pol species: Among the pols tested, the inhibitory effect of the compound on pol $\lambda$ activity was the strongest with $\mathrm{IC}_{50}$ values of 1.6 $\mu \mathrm{M}$. However, sulfobacin B did not influence the activity of plant or prokaryotic pols, or that of the other DNA metabolic enzymes such as primase of pol $\alpha$, RNA poly-
\end{abstract}

Correspondence to: Dr Yoshiyuki Mizushina, Laboratory of Food and Nutritional Sciences, Department of Nutritional Science, KobeGakuin University, Nishi-ku, Kobe, Hyogo 651-2180, Japan

E-mail: mizushin@nutr.kobegakuin.ac.jp

Dr Masaru Yoshida, Division of Gastroenterology, Department of Internal Medicine, Graduate School of Medicine, Kobe University, 7-5-1 Kusunoki-Cho, Chuo-ku, Kobe, Hyogo 650-0017, Japan E-mail: myoshida@med.kobe-u.ac.jp

Abbreviations: pol, DNA polymerase (E.C. 2.7.7.7); TPA, 12-Otetradecanoylphorbol-13-acetate; TNF, tumor necrosis factor; NF, nuclear factor; LPS, lipopolysaccharide; TdT, terminal deoxynucleotidyl transferase; dTTP, 2'-deoxythymidine 5'-triphosphate; DMSO, dimethyl sulfoxide; IE, inhibitory effect; MTT, 3-(4,5dimethylthiazol-2-yl)-2,5-diphenyl tetrazolium bromide; PBS, phosphate-buffered saline; ELISA, enzyme-linked immunosorbent assay; BW, body weight; BER, base excision repair; dRP, 5'-deoxyribose-5-phosphate; AP, apurinic/apyrimidinic

Key words: sulfobacin B, DNA polymerases, enzyme inhibitor, 12-O-tetradecanoylphorbol-13-acetate, lipopolysaccharide, antiinflammation merase, polynucleotide kinase or deoxyribonuclease I. As we previously found a positive relationship between pol $\lambda$ inhibition and anti-inflammation, we examined whether sulfobacin $\mathrm{B}$ could inhibit inflammatory responses. The compound caused a marked reduction in 12-O-tetradecanoylphorbol-13acetate-induced acute inflammation in the mouse ear. In a cell culture system using mouse macrophages, sulfobacin B strongly inhibited the production of tumor necrosis factor (TNF) $-\alpha$ and the action of nuclear factor- $\kappa \mathrm{B}$ induced by lipopolysaccharide (LPS). In an in vivo mouse model of LPSinduced acute inflammation, the intraperitoneal injection of sulfobacin B to mice led to the suppression of serum TNF- $\alpha$ production. These results indicate that sulfobacin $\mathrm{B}$ is a potential chemotherapeutic agent for inflammation.

\section{Introduction}

Sulfobacin B was first isolated from the culture broth of Chryseobacterium sp. in 1995 (1), and has been shown to have bioactivity both as a von Willebrand factor receptor antagonist (1) and a DNA polymerase (pol) $\alpha$ inhibitor (2). Sulfobacin B is a sulfonic acid belonging to a class of unusual sphingosine relatives, and we have chemically synthesized it successfully, as previously described $(3,4)$.

The human genome encodes at least 15 pols that conduct cellular DNA synthesis $(5,6)$. Eukaryotic cells contain 3 replicative pols $(\alpha, \delta$ and $\varepsilon$ ), mitochondrial pol $\gamma$, and at least 11 non-replicative pols $[\beta, \zeta, \eta, \theta, \mathrm{\iota}, \kappa, \lambda, \mu, v$, terminal deoxynucleotidyl transferase (TdT) and REV1] (5-7). Pols have a highly conserved structure, which means that on the whole, their overall catalytic subunits vary very little from species to species. A conserved structure usually indicates that the protein has an important, irreplaceable function in the cell, the maintenance of which provides evolutionary advantages. On the basis of sequence homology, eukaryotic pols can be divided into 4 main different families, termed $\mathrm{A}, \mathrm{B}, \mathrm{X}$ and $\mathrm{Y}$ (8). Family A includes mitochondrial pol $\gamma$, as well as pols $\theta$ and $v$. Family B includes 3 replicative pols $(\alpha, \delta$ and $\varepsilon)$ and pol $\zeta$. Family $\mathrm{X}$ comprises of pols $\beta, \lambda$ and $\mu$, as well as TdT, 
and lastly, family $\mathrm{Y}$ includes pols $\eta, \iota$ and $\kappa$, in addition to REV1. We have been studying the selective inhibitors of each pol from natural materials for $>15$ years $(9,10)$, and we have found that pol $\lambda$ selective inhibitors, such as curcumin derivatives (11-13), have 12-O-tetradecanoylphorbol-13acetate (TPA)-induced anti-inflammatory activity (14-16).

Although tumor promoters are classified as compounds that promote tumor formation (17), they also cause inflammation and are commonly used as artificial inducers of inflammation in order to screen for anti-inflammatory agents (18). Tumor promoter-induced inflammation can be distinguished from acute inflammation, which is exudative and is accompanied by fibroblast proliferation and granulation. The tumor promoter, TPA, is frequently used to search for new types of anti-inflammatory compound. TPA not only causes inflammation, but also influences mammalian cell growth (19), suggesting that the molecular basis of the inflammation stems from the pol reaction related to cell proliferation. This relationship, however, needs to be investigated more closely.

In many inflammatory responses, the activation of nuclear factor $(\mathrm{NF})-\kappa \mathrm{B}$ is the rate-limiting step of the inflammatory mechanism (20). The 5 members of the mammalian NF-kB family, namely p65 (RelA), RelB, c-Rel, p50/p105 (NF-кB1) and p52/p100 (NF-kB2), exist in unstimulated cells as homodimers or heterodimers bound to the proteins of the IкB family (21). The binding of $N F-\kappa B$ to I $\kappa B$ prevents $N F-\kappa B$ from translocating to the nucleus, thereby maintaining $N F-\kappa B$ in an inactive state. $\mathrm{NF}-\kappa \mathrm{B}$ proteins are characterized by the presence of a conserved 300-amino acid Rel homology domain located in the $\mathrm{N}$-terminus of the protein, and this domain is responsible for dimerization with $\mathrm{NF}-\kappa \mathrm{B}$, interaction with I $\kappa \mathrm{B}$ and binding to DNA (21). The translocated NF- $\kappa \mathrm{B}$ proteins function as transcription factors and regulate the expression of various genes that encode pro-inflammatory cytokines such as tumor necrosis factor (TNF)- $\alpha$ and IL-12, which have been shown to play important roles in sustaining inflammatory responses (22-24).

In this study, we investigated the inhibitory effects (IEs) of sulfobacin B, a selective pol inhibitor, on inflammatory responses in vitro and in vivo. We found that this compound suppresses NF- $\mathrm{kB}$ activation induced by lipopolysaccharide (LPS) in mouse macrophage cells. Moreover, we also demonstrate that sulfobacin B exerts IEs against TNF- $\alpha$ production in an animal model of LPS-induced acute inflammation.

\section{Materials and methods}

Materials. Sulfobacin B was chemically synthesized as previously described $(3,4)$, and its structure is shown in Fig. 1. The purification grade of synthesized sulfobacin B was $>98 \%$ pure (data not shown). Nucleotides, such as $\left[{ }^{3} \mathrm{H}\right]-$ deoxythymidine 5'-triphosphate (dTTP) $(43 \mathrm{Ci} / \mathrm{mmol})$, and chemically synthesized DNA template, such as poly(dA), were purchased from GE Healthcare Bio-Sciences (Little Chalfont, UK). DNA primers, such as oligo(dT) $)_{18}$, were customized by Sigma (Hokkaido, Japan). LPS was purchased from Sigma (St. Louis, MO, USA). For Western blot analysis, anti-NF-кB p65 antibody and horseradish peroxidaseconjugated anti-rabbit IgG antibody (i.e. secondary antibody) were obtained from Santa Cruz Biotechnology (Santa Cruz,

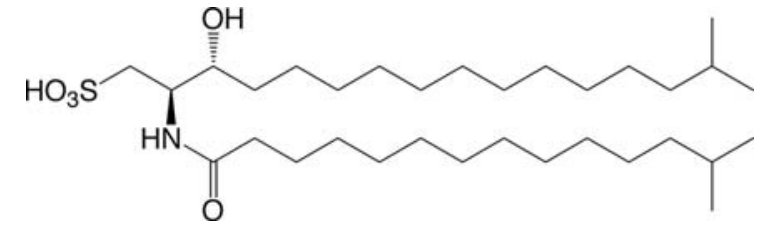

Figure 1. Structure of sulfobacin B.

CA, USA) and Thermo Scientific (Kanagawa, Japan), respectively. All other reagents were of analytical grade and were purchased from Nacalai Tesque Inc. (Kyoto, Japan).

Pols and other DNA metabolic enzyme assays. Pols from mammals, a fish (cherry salmon), an insect (fruit fly) and a plant (cauliflower) were purified, and prokaryotic pols and other DNA metabolic enzymes were purchased as described in our previous study (25). The activities of all the pols and other DNA metabolic enzymes were measured as described in our previous studies (25-27).

The components of the pol assay were poly(dA)/ oligo $(\mathrm{dT})_{18}$ and dTTP as the DNA template-primer and as 2'-deoxyribonucleoside 5'-triphosphate (dNTP) substrate, respectively. Sulfobacin B was dissolved in dimethyl sulfoxide (DMSO) at various concentrations and sonicated for $30 \mathrm{sec}$. The sonicated samples $(4 \mu 1)$ were mixed with $16 \mu 1$ of each pol enzyme (final amount, 0.05 units) in $50 \mathrm{mM}$ Tris- $\mathrm{HCl}$ (pH 7.5) containing $1 \mathrm{mM}$ dithiothreitol, $50 \%$ glycerol and $0.1 \mathrm{mM}$ EDTA, and kept at $0^{\circ} \mathrm{C}$ for $10 \mathrm{~min}$. These inhibitorenzyme mixtures $(8 \mu \mathrm{l})$ were added to $16 \mu \mathrm{l}$ of each standard enzyme reaction mixture [final concentration of $50 \mathrm{mM}$ Tris$\mathrm{HCl}$ (pH 7.5), $1 \mathrm{mM}$ dithiothreitol, $1 \mathrm{mM} \mathrm{MgCl}_{2}, 15 \%$ glycerol, $10 \mu \mathrm{M}$ poly(dA)/oligo(dT) ${ }_{18}$ and $10 \mu \mathrm{M}\left[{ }^{3} \mathrm{H}\right]$-dTTP], and incubation was carried out at $37^{\circ} \mathrm{C}$ for $60 \mathrm{~min}$, except for Taq pol, which was incubated at $74^{\circ} \mathrm{C}$ for $60 \mathrm{~min}$. Activity without the inhibitor was considered to be $100 \%$, and the activity remaining at each concentration of inhibitor was determined relative to this value. One unit of pol activity was defined as the amount of enzyme that catalyzed the incorporation of $1 \mathrm{nmol} \mathrm{dNTP}(\mathrm{dTTP})$ into the synthetic DNA template-primer [poly(dA)/oligo $\left.(\mathrm{dT})_{18}, \mathrm{~A} / \mathrm{T}=2 / 1\right]$ in $60 \mathrm{~min}$ at $37^{\circ} \mathrm{C}$ under normal reaction conditions for each enzyme (scintillation counts: Approximately 1 pmol of incorporated radioactive nucleotides $=100 \mathrm{cpm})(26,27)$.

Animal experiments. All animal studies were performed according to the guidelines outlined in the 'Care and Use of Laboratory Animals' of Kobe-Gakuin University. The animals were anesthetized with pentobarbital before undergoing cervical dislocation. Male 8 -week-old C57BL/6 mice that had been bred in-house with free access to food and water were used for all the experiments. All of the mice were maintained under a 12-h light/dark cycle and housed at a room temperature of $25^{\circ} \mathrm{C}$.

Mouse TPA-induced anti-inflammatory assay. The mouse inflammatory test was performed according to the method described by Gschwendt et al (28). In brief, a methanol solution of the test compound (250 or $500 \mu \mathrm{g} / 20 \mu \mathrm{l}$ ) was 
applied to the inner part of the mouse ear. Thirty minutes after the test compound was applied, a TPA solution $(0.5 \mu \mathrm{g} /$ $20 \mu 1$ of acetone) was applied to the same part of the ear. Methanol, followed by TPA solution, was applied as the control to the other ear of the same mouse. After $7 \mathrm{~h}$, a disk (6 $\mathrm{mm}$ in diameter) was obtained from the ear and weighed. The IE is presented as the ratio of the increase in weight of the ear disks: IE: $\{[($ TPA only)-(tested compound plus TPA)] / [(TPA only)-(vehicle)] x 100\}.

Cell culture of mouse macrophages. A mouse macrophage cell line, RAW264.7, was obtained from the American Type Culture Collection (VA, USA). The cells were cultured in Eagle's minimum essential medium (MEM) supplemented with $4.5 \mathrm{~g}$ of glucose per liter plus $10 \%$ fetal calf serum, $5 \mathrm{mM}$ L-glutamine, 50 units $/ \mathrm{ml}$ penicillin and 50 units $/ \mathrm{ml}$ streptomycin. The cells were cultured at $37^{\circ} \mathrm{C}$ in standard medium in a humidified atmosphere of $5 \% \mathrm{CO}_{2} / 95 \%$ air.

Investigation of cultured RAW264.7 cell growth. A high concentration $(10 \mathrm{mM})$ of sulfobacin $\mathrm{B}$ was dissolved in DMSO and stored. RAW264.7 cells, at $\sim 5 \times 10^{3}$ cells per well were placed in 96-well micro-plates, and then the compound stock solution was diluted to various concentrations and applied to each well. After incubation for $24 \mathrm{~h}$, the survival rate was determined by 3-(4,5-dimethylthiazol-2-yl)-2,5diphenyl tetrazolium bromide (MTT) assay (29).

Preparation of peritoneal macrophages. The mice were injected intraperitoneally with phosphate buffered saline (PBS), and the peritoneal cavity of the mice was washed with PBS. PBS was collected and the peritoneal macrophages were separated from the PBS by centrifugation at $300 \mathrm{x}$ g for 5 min.

Measurement of TNF- $\alpha$ secreted from peritoneal macrophages. The peritoneal macrophages were placed in a 12-well plate at $1 \times 10^{5}$ cells/well and incubated for $24 \mathrm{~h}$. The cells were pre-treated with $0-10 \mu \mathrm{M}$ sulfobacin $\mathrm{B}$ for $30 \mathrm{~min}$ and then stimulated with $100 \mathrm{ng} / \mathrm{ml}$ LPS. After $24 \mathrm{~h}$, the cell culture medium was collected in order to measure the amount of TNF- $\alpha$ secreted. The concentration of TNF- $\alpha$ in the culture medium was quantified using a commercially available enzyme-linked immunosorbent assay (ELISA) development system (Bay Bioscience Co., Ltd., Kobe, Japan) following the manufacturer's instructions.

Cell treatment and preparation of nuclear and whole cellular proteins. The RAW264.7 cells were pre-treated with $10 \mu \mathrm{M}$ sulfobacin B for $30 \mathrm{~min}$ and then treated with $100 \mathrm{ng} / \mathrm{ml}$ LPS. After $30 \mathrm{~min}$, the nuclear proteins and whole cell lysates were isolated from the RAW264.7 cells as described in a previous study (30). The protein concentration of the nuclear function and whole cell lysates were measured using a BCA $^{\text {TM }}$ Protein Assay Kit (Pierce, Rockford, IL) following the manufacturer's instructions. In brief, $25 \mu 1$ of each sample or $2 \mathrm{mg} / \mathrm{ml} \mathrm{BSA}$ solution as a standard, were added to the wells in a 96-well microplate, and then $200 \mu 1$ of BCA working reagent was added to each well. The microplate was incubated at $37^{\circ} \mathrm{C}$ for $30 \mathrm{~min}$, and the protein concentration was determined after the measurement of the absorbance at $575 \mathrm{~nm}$. The nuclear proteins and whole cell lysates were subjected to Western blotting in order to evaluate the nuclear translocation of NF- $\mathrm{KB}$.

Western blotting. The nuclear proteins (30-50 $\mu \mathrm{g}$ protein) and whole cell lysates $(50 \mu \mathrm{g}$ proteins) were boiled in a quarter volume of sample buffer (1 M Tris- $\mathrm{HCl}, \mathrm{pH} 7.5,640 \mathrm{mM} 2-$ mercaptoethanol, $0.2 \%$ bromophenol blue, $4 \%$ SDS and $20 \%$ glycerol) and then separated on $10 \%$ SDS polyacrylamide gels. The proteins in the gels were transferred to a PVDF membrane. The membrane was blocked with $1 \%$ skimmed milk in TBS-T $(10 \mathrm{mM}$ Tris- $\mathrm{HCl}, 100 \mathrm{mM} \mathrm{NaCl}$ and $0.5 \%$ Tween-20) and probed with anti-NF- $\mathrm{B}$ p65 antibody $(1: 1000)$ before the reaction with the horseradish peroxidaseconjugated secondary antibody. The protein-antibody complex was detected using ChemiLumiONE (Nacalai Tesque) and an Image Reader (LAS-3000 imaging system, Fuji Photo Film, Tokyo, Japan). The intensity of each band was analyzed using ImageJ, which was developed at the National Institutes of Health.

In vivo LPS-induced inflammatory experiment. The mice were intraperitoneally injected with $5 \mathrm{mg} / \mathrm{kg}$ body weight (BW) of sulfobacin B dissolved in corn oil, or $200 \mu \mathrm{l}$ of corn oil as the vehicle control. After $30 \mathrm{~min}$, the mice were intraperitoneally injected with $250 \mu \mathrm{g} / \mathrm{kg}$ BW LPS dissolved in PBS or $200 \mu \mathrm{l}$ of PBS as the vehicle control. After $1 \mathrm{~h}$, the mice were sacrificed, and blood samples were collected. The blood serum was separated by centrifugation at 15,000 x g for $10 \mathrm{~min}$ at $4^{\circ} \mathrm{C}$. The TNF- $\alpha$ level in the serum was measured using ELISA.

Statistical analysis. All data are expressed as the means \pm SE of at least 3 independent determinations for each experiment. Statistical significance was analyzed using the Student's ttest, and a level of probability of 0.05 was used as the criterion of significance.

\section{Results}

Effects of sulfobacin B on pols and other DNA metabolic enzymes. As described previously (2), sulfobacin B acts as a pol $\alpha$ inhibitor, and therefore we first investigated the biochemical actions of chemically synthesized sulfobacin B in vitro. As described briefly in the Introduction, we succeeded in obtaining 10 eukaryotic pol species including pols $\alpha, \beta, \gamma$, $\delta, \varepsilon, \mathrm{l}, \eta, \kappa$ and $\lambda$, as well as TdT. However, pols $\xi, \theta, \mu$ and $\nu$, and REV1 are not yet available (Table I). Eukaryotes express at least 15 species of pols $(5,6)$, and we are still in an era when most pols are very difficult to obtain in their purified form in a laboratory. Table I shows the IE $\left(\mathrm{IC}_{50}\right.$ value) of sulfobacin B against these various pol species. This compound inhibited the activity of all of the pols from mammals, fish and insects, and $50 \%$ inhibition was observed at a dose of 1.6-5.7 $\mu \mathrm{M}$. The dose-response inhibition curves of sulfobacin B against human pol $\gamma$, calf pol $\alpha$, and human pols $\lambda$ and $\kappa$, which are representative of the A, B, X and Y families of pols, respectively, are shown in Fig. 2. Sulfobacin B showed the strongest inhibition of pol $\lambda$ among the pols 
Table I. $\mathrm{IC}_{50}$ values of sulfobacin $\mathrm{B}$ against the activity of various DNA polymerases and other DNA metabolic enzymes.

\begin{tabular}{cc}
\hline Enzyme & $\mathrm{IC}_{50}$ value of \\
sulfobacin $\mathrm{B}(\mu \mathrm{M})$
\end{tabular}

Mammalian pols

A family of pols

Human pol $\gamma$

$4.4 \pm 0.22$

B family of pols

Calf pol $\alpha$

Human pol $\delta$

$3.0 \pm 0.16$

Human pol $\varepsilon$

$3.1 \pm 0.17$

$\mathrm{X}$ family of pols

Rat pol $\beta$

$1.9 \pm 0.11$

Human pol $\lambda$

$1.6 \pm 0.09$

Calf TdT

$2.1 \pm 0.12$

Y family of pols

Human pol $\eta$

$4.6 \pm 0.24$

Mouse pol ı

$4.5 \pm 0.22$

Human pol $\kappa$

$4.1 \pm 0.21$

Fish pols

Cherry salmon pol $\delta$

$3.5 \pm 0.19$

Insect pols

Fruit fly pol $\alpha$

$4.3 \pm 0.22$

Fruit fly pol $\delta$

$5.7 \pm 0.30$

Fruit fly pol $\varepsilon$

$4.8 \pm 0.25$

Plant pols

Cauliflower pol $\alpha$

Prokaryotic pols

E. coli pol I

Taq pol

T4 pol

Other DNA metabolic enzymes

Calf primase of pol $\alpha$

T7 RNA polymerase

T4 polynucleotide kinase

Bovine deoxyribonuclease I
Sulfobacin B was incubated with each enzyme. Enzymatic activity was measured as described in Materials and methods. Enzyme activity in the absence of the compounds was taken as $100 \%$. Data are expressed as the means \pm SEM of 3 independent experiments.

investigated, with an $\mathrm{IC}_{50}$ value of $1.6 \mu \mathrm{M}$. The IE of sulfobacin $\mathrm{B}$ on the $\mathrm{X}$ family of pols, such as pols $B$ and $\lambda$ and TdT, was stronger than that on the A, B and Y families of pols (Table I).

On the contrary, sulfobacin B had no effect on plant (cauliflower) pol $\alpha$ or prokaryotic pols, such as E. coli pol I,

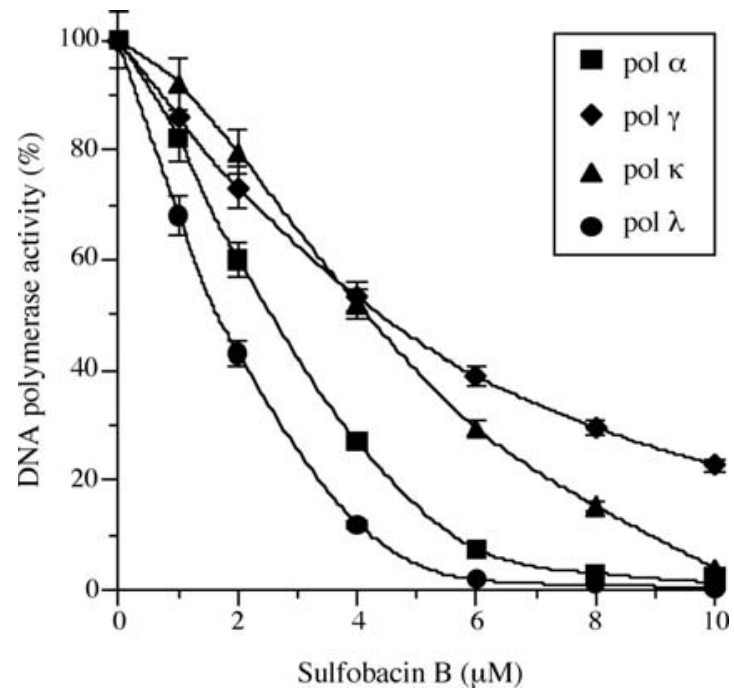

Figure 2. Mammalian pol inhibition dose-response curves of sulfobacin B. Sulfobacin B $(0-10 \mu \mathrm{M})$ was incubated with calf pol $\alpha$ (B family of pols, square), human pol $\gamma$ (A family of pols, diamond), human pol $\kappa$ (Y family of pols, triangle) or human pol $\lambda$ (X family of pols, circle) (each at 0.05 units). Pol activity was measured as described in Materials and methods. Pol activity in the absence of the compounds was taken as $100 \%$. Data are expressed as the means \pm SE of 3 independent experiments.

Taq pol or T4 pol (Table I). The 3-dimensional structures of eukaryotic pols are likely to differ greatly from those of prokaryotic pols. Sulfobacin B did not inhibit the activity of other DNA metabolic enzymes, such as calf primase pol $\alpha$, T7 RNA polymerase, T4 polynucleotide kinase, or bovine deoxyribonuclease I. These results suggest that sulfobacin B could be a selective inhibitor of animal pols, especially the $\mathrm{X}$ family of pols containing pol $\lambda$.

In order to test whether sulfobacin B is an intercalating agent that distorts DNA and subsequently inhibits enzyme activity, we measured the thermal transition of DNA in the presence or absence of this compound. The thermal transition profile of DNA was the same with or without sulfobacin B (data not shown). Therefore, the inhibition of pols by sulfobacin B is not due to DNA distortion, but due to the direct effect of this compound on the enzymes themselves.

Effect of sulfobacin B on TPA-induced anti-inflammatory activity. In a pol inhibitor study, we previously found that a relationship exists between pol $\lambda$ inhibitors and TPA-induced acute anti-inflammatory activity $(10,14,15)$. Therefore, using the mouse ear inflammatory test, we examined the antiinflammatory activity of sulfobacin B. The application of TPA $(0.5 \mu \mathrm{g})$ to the mouse ear induced edema, and the increase in weight of the ear disk $7 \mathrm{~h}$ after application was $241 \%$. As shown in Table II, the pre-treatment with 250 and $500 \mu \mathrm{g}$ of sulfobacin B suppressed the inflammation, with an IE of 48 and $81.5 \%$, respectively. The application of sulfobacin B resulted in stronger reduction of TPA-induced inflammation than the one observed with curcumin, a major anti-inflammatory compound (31). We previously reported that curcumin has specific inhibitory activity against the mammalian pol $\lambda$, and $50 \%$ inhibition was observed at a concentration of $7 \mu \mathrm{M}(10,14,15)$. The inhibition of pol $\lambda$ was more profound by sulfobacin B than by curcumin. Thus, 
Table II. Anti-inflammatory activity of sulfobacin B and curcumin in the mouse ear inflammation test.

\begin{tabular}{lcc}
\hline Compound & \multicolumn{2}{c}{ IE (\%) } \\
\cline { 2 - 3 } & $250 \mu \mathrm{g} / \mathrm{ear}$ & $500 \mu \mathrm{g} / \mathrm{ear}$ \\
\hline Sulfobacin B & $48.0 \pm 6.3$ & $81.5 \pm 11.6$ \\
Curcumin & $36.2 \pm 5.4$ & $67.8 \pm 9.5$ \\
\hline
\end{tabular}

A sample of the test compound ( 250 or $500 \mu \mathrm{g}$ ) was applied to 1 mouse ear and, after $30 \mathrm{~min}$, TPA $(0.5 \mu \mathrm{g})$ was applied to both ears of the mouse. The edema was evaluated after $7 \mathrm{~h}$, the IE being expressed as the percentage ratio of the edema. Data are expressed as the means \pm SE of 6 mice used for each experiment.

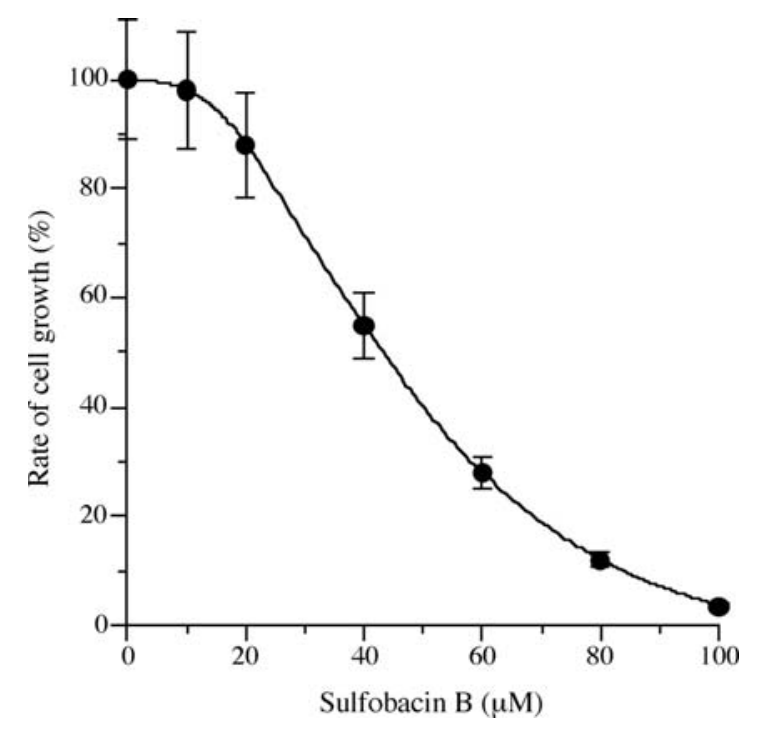

Figure 3. Macrophage cell growth inhibition dose-response curves of sulfobacin B. Various concentrations $(0-100 \mu \mathrm{M})$ of sulfobacin B were incubated with mouse RAW264.7 macrophage cells for $24 \mathrm{~h}$. The rate of cell growth was determined by MTT assay (29). Data are expressed as the means \pm SE of 5 independent experiments.

these results suggest that the inhibition of the activity of pol $\lambda$ has a positive correlation with anti-inflammatory activity.

Effects of sulfobacin B on mouse macrophage cell growth. In order to clarify the cytological effects of sulfobacin B, the influence of this compound on mouse macrophage RAW264.7 cultured cell growth was investigated, whereby the cells were incubated with sulfobacin B for 24 h. As shown in Fig. 3, sulfobacin B had no effect on the proliferation of this cell line at low concentrations up to $10 \mu \mathrm{M}$. However, concentrations $>10 \mu \mathrm{M}$ were found to dose-dependently suppress the growth of RAW264.7 cells, with an $\mathrm{LD}_{50}$ value of $43.2 \mu \mathrm{M}$. This value is $\sim 10$-fold the $\mathrm{IC}_{50}$ value of sulfobacin $\mathrm{B}$ against the activity of mammalian pols including pol $\lambda$, which is a repair and/or recombination pol $(32,33)$, and this inhibition is mostly mediated through the function of these pols. Curcumin, which is a pol- $\lambda$-specific inhibitor, also suppressed RAW264.7
A

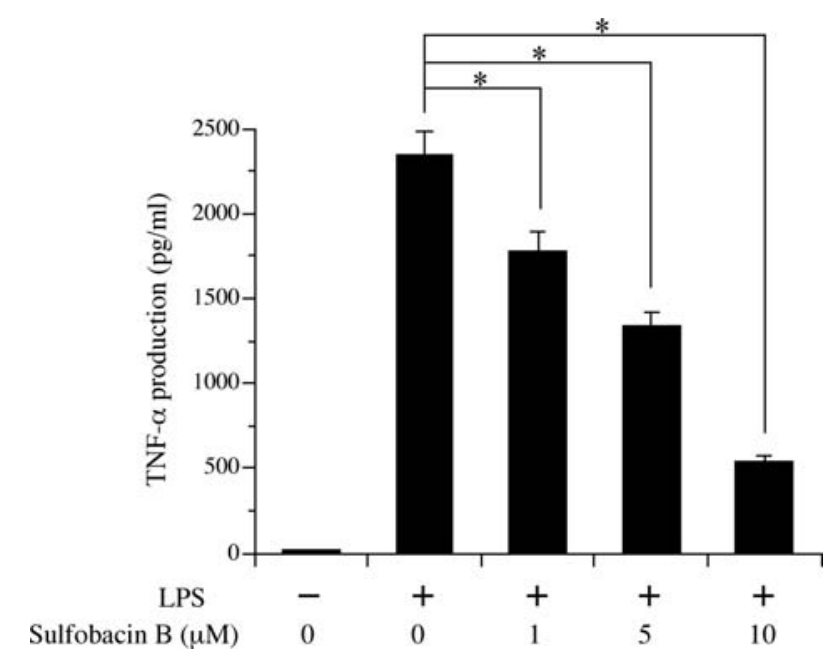

$\mathrm{B}$

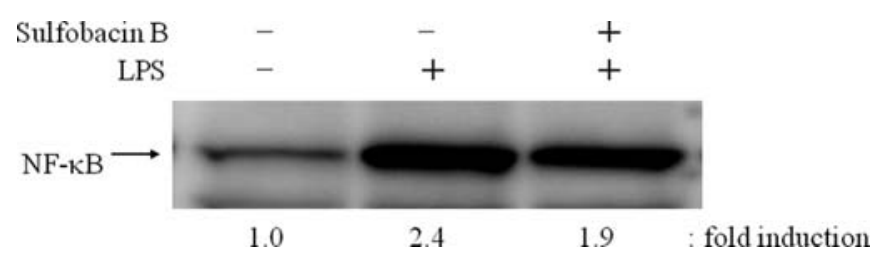

Figure 4. IEs of sulfobacin B on LPS-induced production of TNF- $\alpha$ in peritoneal macrophages and nuclear translocation of NF- $\mathrm{BB}$ in RAW264.7 cells. (A) The peritoneal macrophages were pre-treated with $0-10 \mu \mathrm{M}$ sulfobacin B as the vehicle control for $30 \mathrm{~min}$ and then treated with $100 \mathrm{ng} /$ ml LPS for $24 \mathrm{~h}$, and the TNF- $\alpha$ concentration in the cell medium was measured by ELISA. Data are expressed as the means \pm SE $(n=4)$. *Significant difference according to the Student's t-test $(\mathrm{p}<0.05)$. (B) RAW264.7 cells were incubated with $10 \mu \mathrm{M}$ sulfobacin B or DMSO (none), as the vehicle control for $30 \mathrm{~min}$, and then treated with $100 \mathrm{ng} / \mathrm{ml}$ LPS for $30 \mathrm{~min}$. The nuclear proteins were prepared from the cells and were subjected to Western blot analysis for the evaluation of the nuclear translocation of NF- $\mathrm{B}$ p 65 . The intensity of each band was analyzed, and the values relative to treatment without LPS (negative control) are represented at the lower edge of the image.

cell growth, and $50 \%$ inhibition was observed at a concentration of $62.5 \mu \mathrm{M}$. These results suggest that sulfobacin $\mathrm{B}$ could penetrate these macrophage cells and reach the nucleus, thereby inhibiting the activities of mammalian pols including pol $\lambda$.

Inhibitory effects of sulfobacin B on LPS-induced inflammatory responses in cultured macrophage cells and peritoneal macrophages. Next, we investigated whether sulfobacin B can inhibit both the reduction of $\mathrm{TNF}-\alpha$ production in peritoneal macrophages and the nuclear translocation of NF-кB p65 induced by LPS stimulation in RAW264.7 cells. The inflammatory cytokine, TNF- $\alpha$, activates the NF- $\mathrm{kB}$ signaling pathway by binding to the $\mathrm{TNF}-\alpha$ receptor, and thereby initiating an inflammatory response, resulting in various inflammatory diseases (34). In RAW264.7 cells, the cytotoxicity of sulfobacin B at $10 \mu \mathrm{M}$ was not observed (Fig. 3). As shown in Fig. 4A, the cells produced $2300 \mathrm{pg} / \mathrm{ml}$ of TNF- $\alpha$ after LSP treatment, and sulfobacin B $(0-10 \mu \mathrm{M})$ dose-dependently suppressed this LPS-stimulated production 


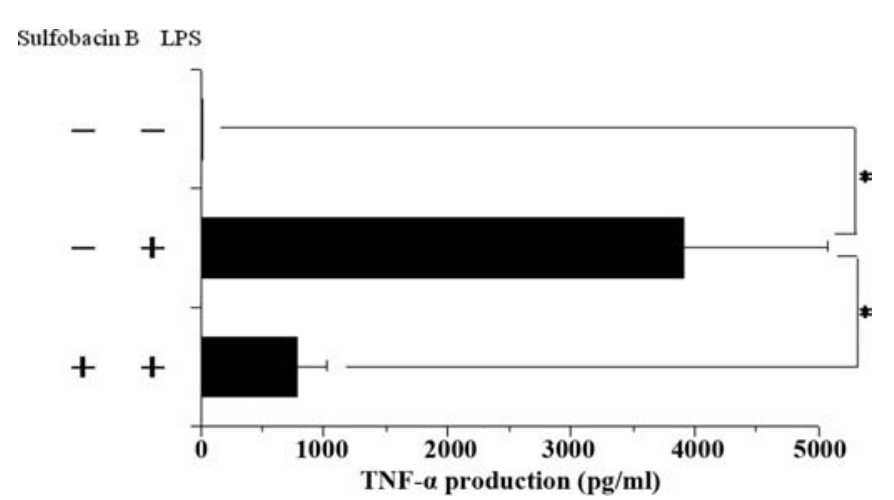

Figure 5. The inhibitory activity of sulfobacin B against LPS-induced inflammation in vivo. Male C57BL/6 mice were intraperitoneally injected sulfobacin B at $5 \mathrm{mg} / \mathrm{kg} \mathrm{BW}$ or corn oil as a vehicle control. After $30 \mathrm{~min}$, the mice were intraperitoneally injected with LPS at $250 \mu \mathrm{g} / \mathrm{kg} \mathrm{BW}$ or saline as a vehicle control. One hour after the LPS injection, the mice were sacrificed, and the TNF- $\alpha$ level in serum was measured using ELISA. Data value are expressed as the mean \pm SE of duplicate measurements of 3 experiments. Asterisks indicate a significant difference $(\mathrm{p}<0.05)$. Treatment with corn oil and LPS was a positive control (TNF- $\alpha$ level, $3,899 \mathrm{pg} / \mathrm{ml}$ ), and that with corn oil and saline was a negative control (TNF- $\alpha$ level, $17 \mathrm{pg} / \mathrm{ml}$ ).

of TNF- $\alpha$. At $10 \mu \mathrm{M}$, the significant suppressive effect of the compound on TNF- $\alpha$ production was confirmed, with a reduction of $77 \%$.

$\mathrm{NF}-\kappa \mathrm{B}$ is known to be the rate-controlling factor for inflammatory responses. Therefore, we examined the IEs of sulfobacin $\mathrm{B}$ on the LPS-induced nuclear translocation of NF- $\mathrm{B}$ in RAW264.7 cells (Fig. 4B). By Western blot analysis, it was revealed that the amount of NF- $\mathrm{B}$ nuclear translocation in RAW264.7 cells was 2.4-fold higher after LPS treatment, and that $10 \mu \mathrm{M}$ sulfobacin $\mathrm{B}$ inhibited this LPS-stimulated nuclear translocation of NF- $\kappa \mathrm{B}$. These results demonstrate that sulfobacin $\mathrm{B}$ can suppress the nuclear translocation of NF- $\mathrm{KB}$ by inhibiting the production of TNF- $\alpha$.

Inhibitory effect of sulfobacin B on LPS-induced inflammation in vivo. In order to assess the anti-inflammatory effects of sulfobacin B in vivo, we investigated the inhibitory activity of this compound against LPS-induced acute inflammation (Fig. 5). Treatment with $250 \mu \mathrm{g} / \mathrm{kg}$ BW of LPS significantly increased the serum TNF- $\alpha$ level, and the intraperitoneal injection of $5 \mathrm{mg} / \mathrm{kg} \mathrm{BW}$ of sulfobacin B decreased this LPSinduced TNF- $\alpha$ production to $79.9 \%$. Thus, the in vivo data obtained from the mouse show the same tendency as the data obtained from cultured mouse macrophage cells (Fig. 4).

\section{Discussion}

We have shown here that synthetic sulfobacin B, a sulfonolipid (Fig. 1) selectively inhibits the activity of animal pols, especially the $\mathrm{X}$ family of pols such as pol $\lambda$, among the DNA metabolic enzymes tested (Table I and Fig. 2), and that this compound could be a novel therapeutic agent for chronic inflammation (Table II, Figs. 4 and 5). As reported previously, a phenolic compound, curcumin, which is a known antiinflammatory agent, is a pol $\lambda$-specific inhibitor $(10,14,15)$. The fact that the major molecular target of sulfobacin $B$ is pol $\lambda$, is of great interest.
Eukaryotic cells reportedly contain 15 pol species consisting of 4 families: Namely, family A (pols $\gamma, \theta$ and $v$ ), family $\mathrm{B}$ (pols $\alpha, \delta, \varepsilon$ and $\zeta$ ), family $\mathrm{X}$ (pols $\beta, \lambda, \mu$ and TdT) and family $Y$ (pols $\eta, \iota, \kappa$ and REV1) (5-8). Among the $\mathrm{X}$ family of pols, the biochemical function of pol $\lambda$ is not yet clear. However, pol $\lambda$ functions in a manner similar to pol $\beta$ (33). Pol $\beta$ not only is involved in the short-patch base excision repair (BER) pathway (35-38), but also plays an essential role in neural development (39). Pol $\lambda$ has been found to contain 5'-deoxyribose-5-phosphate (dRP), but no apurinic/ apyrimidinic (AP) lyase activity (40), and to be able to substitute for pol $\beta$ during in vitro BER, suggesting that pol $\lambda$ also participates in BER. Northern blot analysis has indicated that transcripts of pol $\beta$ are abundantly expressed in the testis, thymus and brain in rats (41), whereas pol $\lambda$ is efficiently transcribed mostly in the testis (32). Bertocci et al have reported that mice in which pol $\lambda$ is knocked down, are not only viable and fertile, but also display a normal hypermutation pattern (42).

TPA not only causes inflammation, but also influences cell proliferation and has physiological effects on cells as it is a tumor promoter (19). Therefore, anti-inflammatory agents are expected to suppress both mammalian cell proliferation and DNA replication/repair in the nuclei in relation to the action of TPA. As pol $\lambda$ is a repair-related pol (33), our finding that the molecular target of sulfobacin B is pol $\lambda$ is in agreement with this expected mechanism of anti-inflammatory agents. As a result, a pol $\lambda$ inhibitor could also be an inhibitor of chronic inflammation.

In this study, our results also revealed that sulfobacin B suppressed LPS-evoked inflammatory responses in vitro and in vivo. Our study is the first to demonstrate that sulfobacin $\mathrm{B}$ reduces $\mathrm{NF}-\kappa \mathrm{B}$ activation and $\mathrm{TNF}-\alpha$ production. The molecular mechanism linking the LPS-induced inflammatory response and anti-inflammatory activity in the model of TPA-induced ear edema is not yet known. As the activated $\mathrm{NF}-\kappa \mathrm{B}$ has been observed in a model of TPA-induced ear edema (43), the anti-inflammatory effects of sulfobacin B could at least in part be dependent on the inhibition of NF- $\mathrm{KB}$ activation. Our study indicates that sulfobacin B is useful as an NF- $\mathrm{KB}$ inhibitor and could be a potent chemopreventive agent against inflammation.

In conclusion, we investigated the mode of action of the sulfobacin B inhibition of pols, which are responsible for DNA replication leading to cell proliferation and DNA repair/recombination, as well as for the relationship between the degree of the cell growth IE and anti-inflammatory activity. As a result, we found a positive relationship between the pol inhibitory and anti-inflammatory activities. The correlation between these activities could be useful as a new and convenient in vitro assay to screen for novel anti-inflammatory compounds.

\section{Acknowledgements}

We are grateful for the donations of calf pol $\alpha$ by Dr M. Takemura of the Tokyo University of Science (Tokyo, Japan), rat pol $\beta$, and human pols $\delta$ and $\varepsilon$ by Dr K. Sakaguchi of the Tokyo University of Science (Chiba, Japan), human pol $\gamma$ by Dr M. Suzuki of the Nagoya University School of Medicine 
(Nagoya, Japan), human pols $\eta$ and ı by Drs F. Hanaoka and C. Masutani of Osaka University (Osaka, Japan), human pol $\kappa$ by Dr H. Ohmori of Kyoto University (Kyoto, Japan), and human pol $\lambda$ by Dr O. Koiwai of the Tokyo University of Science (Chiba, Japan). This study was supported in part by the Global COE Program 'Global Center of Excellence for Education and Research on Signal Transduction Medicine in the Coming Generation' from the Ministry of Education, Culture, Sports, Science and Technology of Japan (MEXT) (T.A. and M.Y.), and a Grant-in-Aid for 'Academic Frontier' Project for Private Universities: Matching fund subsidy from MEXT, 2006-2010 (H.Y. and Y.M.). Y.M. acknowledges a Grant-in-Aid for Young Scientists (A) (no. 19680031) from MEXT.

\section{References}

1. Kamiyama T, Umino T, Satoh T, Sawairi S, Shirane M, Ohshima S and Yokose K: Sulfobacins A and B, novel von Willebrand factor receptor antagonists. I. Production, isolation, characterization and biological activities. J Antibiot (Tokyo) 48: 924-928, 1995.

2. Kohayashi J, Mikami S, Shigemori H, Takao T, Shimonishi Y, Izuta S and Yoshida S: Flavocristamides A and B, new DNA polymerase $\alpha$ inhibitors from a marine bacterium Flavobacterium $\mathrm{sp}$. Tetrahedron 51: 10487-10490, 1995.

3. Takikawa H, Muto S, Nozawa D, Kayo A and Mori K: Synthesis of sulfobacin A and B, new sulfonolipids isolated from Chryseobacterium sp. Tetrahedron Lett 39: 6931-6934, 1998.

4. Takikawa H, Nozawa D, Kayo A, Muto S and Mori K: Synthesis of sphingosine relatives. Part 22.1 Synthesis of sulfobacin A, B and flavocristamide A, new sulfonolipids isolated from Chryseobacterium sp. J Chem Soc (Perkin Trans) 1: 2467-2477, 1999 .

5. Hubscher U, Maga G and Spadari S: Eukaryotic DNA polymerases. Annu Rev Biochem 71: 133-163, 2002.

6. Bebenek K and Kunkel TA: Functions of DNA polymerses in DNA repair and replication. In: Advances in Protein Chemistry. Yang W (ed). Vol. 69. Elsevier, San Diego, pp137-165, 2004.

7. Takata K, Shimizu T, Iwai S and Wood RD: Human DNA polymerase $\mathrm{N}$ (POLN) is a low fidelity enzyme capable of error-free bypass of 5S-thymine glycol. J Biol Chem 281: 23445-23455, 2006.

8. Friedberg EC, Feaver WJ and Gerlach VL: The many faces of DNA polymerases: strategies for mutagenesis and for mutational avoidance. Proc Natl Acad Sci USA 97: 5681-5683, 2000.

9. Sakaguchi K, Sugawara F and Mizushina Y: Inhibitors of eukaryotic DNA polymerases. Seikagaku 74: 244-251, 2002.

10. Mizushina Y: Specific inhibitors of mammalian DNA polymerase species. Biosci Biotechnol Biochem 73: 1239-1251, 2009.

11. Mizushina Y, Kamisuki S, Kasai N, Ishidoh T, Shimazaki N, Takemura M, Asahara H, Linn S, Yoshida S, Koiwai O, Sugawara F, Yoshida H and Sakaguchi K: Petasiphenol: a DNA polymerase $\lambda$ inhibitor. Biochemistry 41: 14463-14471, 2002.

12. Mizushina Y, Ishidoh T, Takeuchi T, Shimazaki N, Koiwai O, Kuramochi K, Kobayashi S, Sugawara F, Sakaguchi K and Yoshida H: Monoacetylcurcumin: a new inhibitor of eukaryotic DNA polymerase $\lambda$ and a new ligand for inhibitor-affinity chromatography. Biochem Biophys Res Commun 337: 1288-1295, 2005 .

13. Takeuchi T, Ishidoh T, Iijima H, Kuriyama I, Shimazaki N, Koiwai O, Kuramochi K, Kobayashi S, Sugawara F, Sakaguchi K, Yoshida $\mathrm{H}$ and Mizushina Y: Structural relationship of curcumin derivatives binding to the BRCT domain of human DNA polymerase $\lambda$. Genes Cells 11: 223-235, 2006.

14. Mizushina Y, Hirota M, Murakami C, Ishidoh T, Kamisuki S, Shimazaki N, Takemura M, Perpelescu M, Suzuki M, Yoshida H, Sugawara F, Koiwai O and Sakaguchi K: Some anti-chronic inflammatory compounds are DNA polymerase $\lambda$-specific inhibitors. Biochem Pharmacol 66: 1935-1944, 2003.
15. Mizushina Y, Takeuchi T, Kuramochi K, Kobayashi S, Sugawara F, Sakaguchi K and Yoshida H: Study on the molecular structure and bio-activity (DNA polymerase inhibitory activity, anti-inflammatory activity and anti-oxidant activity) relationship of curcumin derivatives. Curr Bioactive Compounds 3: 171-177, 2007.

16. Nishida M, Nishiumi S, Mizushina Y, Fujishima Y, Yamamoto K, Masuda A, Mizuno S, Fujita T, Morita Y, Kutsumi H, Yoshida H, Azuma T and Yoshida M: Monoacetylcurcumin strongly regulates inflammatory responses through inhibition of NF-кB activation. Int J Mol Med 25: 761-767, 2010.

17. Hecker E: Carcinogenesis. Raben Press, New York, pp11-48, 1978.

18. Fujiki H and Sugimura T: Advances in Cancer Research. Academic Press Inc., London, pp223-264, 1987.

19. Nakamura Y, Murakami A, Ohto Y, Torikai K, Tanaka T and Ohigashi H: Suppression of tumor promoter-induced oxidative stress and inflammatory responses in mouse skin by a superoxide generation inhibitor 1'-acetoxychavicol acetate. Cancer Res 58: 4832-4839, 1995.

20. Huang TT and Wuerzberger-Davis SM: Sequential modification of NEMO/IKK $\gamma$ by SUMO-1 and ubiquitin mediates NF- $\kappa$ B activation by genotoxic stress. Cell 115: 565-576, 2003.

21. Hayden MS and Ghosh S: Signaling to NF-кB. Genes Dev 18: 2195-2224, 2004

22. Bonizzi G and Karin M: The two NF-kappaB activation pathways and their role in innate and adaptive immunity. Trends Immunol 25: 280-288, 2004.

23. Wajant H, Pfizenmaier K and Scheurich P: Tumor necrosis factor signaling. Cell Death Differ 10: 45-65, 2003.

24. Elson CO, Sartor RB, Tennyson GS and Riddell RH: Experimental models of inflammatory bowel disease. Gastroenterology 109: 1344-1367, 1995.

25. Mizushina Y, Motoshima H, Yamaguchi Y, Takeuchi T, Hirano K, Sugawara $\mathrm{F}$ and Yoshida $\mathrm{H}$ : 3-O-methylfunicone, a selective inhibitor of mammalian Y-family DNA polymerases from an Australian sea salt fungal strain. Mar Drugs 7: 624-639, 2009.

26. Mizushina Y, Tanaka N, Yagi H, Kurosawa T, Onoue M, Seto H, Horie T, Aoyagi N, Yamaoka M, Matsukage A, Yoshida S and Sakaguchi K: Fatty acids selectively inhibit eukaryotic DNA polymerase activities in vitro. Biochim Biophys Acta 1308: 256-262, 1996.

27. Mizushina Y, Yoshida S, Matsukage A and Sakaguchi K: The inhibitory action of fatty acids on DNA polymerase B. Biochim Biophys Acta 1336: 509-521, 1997.

28. Gschwendt M, Kittstein W, Furstenberger G and Marks F: The mouse ear edema: a quantitatively evaluable assay for tumor promoting compounds and for inhibitors of tumor promotion. Cancer Lett 25: 177-185, 1984.

29. Mosmann T: Rapid colorimetric assay for cellular growth and survival: application to proliferation and cytotoxicity assays. J Immunol Methods 65: 55-63, 1983.

30. Nishiumi S, Yamamoto N, Kodoi R, Fukuda I, Yoshida K and Ashida $\mathrm{H}$ : Antagonistic and agonistic effects of indigoids on the transformation of an aryl hydrocarbon receptor. Arch Biochem Biophys 470: 187-199, 2008.

31. Jurenka JS: Anti-inflammatory properties of curcumin, a major constituent of Curcuma longa: a review of preclinical and clinical research. Altern Med Rev 14: 141-153, 2009.

32. Garcia-Diaz M, Dominguez O, Lopez-Fernandez LA, De Lera LT, Saniger ML, Ruiz JF, Parraga M, Garcia-Ortiz MJ, Kirchhoff T, Del Mazo J, Bernad A and Blanco L: DNA polymerase $\lambda$, a novel DNA repair enzyme in human cells. J Mol Biol 301: 851-867, 2000.

33. Garcia-Diaz M, Bebenek K, Sabariegos R, Dominguez O, Rodriguez J, Kirchhoff T, Garcia-Palomero E, Picher AJ, Juarez R, Ruiz JF, Kunkel TA and Blanco L: DNA polymerase $\lambda$, a novel DNA repair enzyme in human cells. J Biol Chem 277 : 13184-13191, 2002.

34. Aggarwal BB: Signalling pathways of the TNF superfamily: a double-edged sword. Nat Rev Immunol 3: 745-756, 2003

35. Singhal RK and Wilson SH: Short gap-filling synthesis by DNA polymerase $B$ is processive. J Biol Chem 268: 15906-15911, 1993.

36. Matsumoto $\mathrm{Y}$ and Kim K: Excision of deoxyribose phosphate residues by DNA polymerase $\beta$ during DNA repair. Science 269: 699-702, 1995.

37. Sobol RW, Horton JK, Kuhn R, Gu H, Singhal RK, Prasad R, Rajewsky K and Wilson SH: Requirement of mammalian DNA polymerase- $\beta$ in base-excision repair. Nature 379: 183-186, 1996. 
38. Ramadan K, Shevelev IV, Maga G and Hubscher U: DNA polymerase $\lambda$ from calf thymus preferentially replicates damaged DNA. J Biol Chem 277: 18454-18458, 2002.

39. Sugo N, Aratani Y, Nagashima Y, Kubota Y and Koyama H: Neonatal lethality with abnormal neurogenesis in mice deficient in DNA polymerase B. EMBO J 19: 1397-1404, 2000.

40. Garcia-Diaz M, Bebenek K, Kunkel TA and Blanco L: Identification of an intrinsic 5'-deoxyribose-5-phosphate lyase activity in human DNA polymerase $\lambda$ : a possible role in base excision repair. J Biol Chem 276: 34659-34663, 2001.

41. Hirose F, Hotta Y, Yamaguchi M and Matsukage A: Difference in the expression level of DNA polymerase $\beta$ among mouse tissues: high expression in the pachytene spermatocyte. Exp Cell Res 181: 169-180, 1989.
42. Bertocci B, De Smet A, Flatter E, Dahan A, Bories JC, Landreau C, Weill JC and Reynaud CA: Cutting edge: DNA polymerases $\mu$ and $\lambda$ are dispensable for Ig gene hypermutation. J Immunol 168: 3702-3706, 2002.

43. Medeiros R, Otuki MF, Avellar MC and Calixto JB: Mechanisms underlying the inhibitory actions of the pentacyclic triterpene alpha-amyrin in the mouse skin inflammation induced by phorbol ester 12-O-tetradecanoylphorbol-13-acetate. Eur J Pharmacol 559: 227-235, 2007. 